RAE-IC, Revista de la Asociación Española de Investigación de la Comunicación vol. 8, núm. 15 (2021), 429-451 ISSN 2341-2690

Recibido el 25 de noviembre de 2020 DOI: https://doi.org/10.24137/raeic.8.15.19 Aceptado el 11 de diciembre de 2020

\title{
La construcción de la información periodística sobre la COVID-19 en la prensa local argentina
}

The construction of information on COVID-19 in the Argentine local press

\author{
Sánchez, María del Rosario \\ IIESS, Universidad Nacional del Sur (UNS), CONICET. \\ Facultad de Ciencias Sociales, Universidad de Buenos Aires (UBA) \\ rosariosanchezrod@gmail.com
}

Forma de citar este artículo:

Sánchez, R. (2021). La construcción de la información periodística sobre la COVID-19 en la prensa local argentina. RAE-IC, Revista de la Asociación Española de Investigación de la Comunicación, 8(15), 429-451. https://doi.org/10.24137/raeic.8.15.19

\section{Resumen:}

Este trabajo analiza la construcción que los medios de comunicación argentinos hacen de la pandemia producida por el coronavirus y sus efectos en el territorio. Se focaliza en la prensa de carácter local, específicamente de la ciudad de Bahía Blanca, localidad de gran importancia en el mapa productivo del país.

Se estudia la agenda temática que el principal diario de la ciudad y su hinterland, La Nueva, construye sobre la COVID-19, los temas o problemas que considera relevantes y jerarquiza en el período abordado. Asimismo, se analizan los principales encuadres o frames presentes en los discursos, asumiendo que constituyen marcos interpretativos 
de la realidad social que tienen impacto en el debate público y en las respuestas que ofrece el sistema político a la problemática. El objetivo principal es realizar una aproximación al tipo de información que recibe la sociedad de Bahía Blanca y la región sobre la problemática en un momento crítico mundial.

Palabras clave: prensa local, Argentina, COVID-19, agenda, encuadre

\section{Abstract:}

This article analyzes the construction that Argentine media make of the pandemic produced by the coronavirus in Argentina and its effects on the territory. It focuses on the local press, specifically of the city of Bahía Blanca, a town of great importance on the country's productive map.

The work studies the agenda that the main newspaper of the city and its hinterland, $L a$ Nueva, builds on COVID-19, the issues or problems that it considers relevant and hierarchical in the period covered. Likewise, it analyzes the main frames present in the discourses, assuming that they constitute interpretive frames of social reality that have an impact on public debate and on the responses that the political system offers to the problem. The main objective is to make an approximation to the type of information that the society of Bahía Blanca and the region receives on the problem at a critical global moment.

Keywords: local press, Agentina, COVID-19, agenda, framing

\section{INTRODUCCIÓN}

El 3 de marzo de 2020 la Argentina reportó su primer caso de COVID-19, identificado en la Ciudad de Buenos Aires, capital del país. El virus llegó al territorio casi tres meses después de que se registrara el denominado paciente cero a nivel global, en la ciudad de Wuhan, China. 
Los medios de comunicación argentinos, que informaban acerca del avance y los efectos de la pandemia en el mundo ${ }^{1}$, intensificaron sus coberturas cuando fue diagnosticado el primer caso en Argentina. En particular, la prensa gráfica de mayor circulación instaló el tema en sus portadas, espacio de mayor jerarquía informativa (Verón, 1983), con titulares destacados como Un Argentino que volvió de Europa es el primer caso de coronavirus en el país (Clarín, 4/3/20); Alarma en la Argentina: confirman el primer caso de coronavirus en el país (La Nación, 4/3/20), Que no cunda el pánico (P12, 4/3/20). En tanto, la prensa digital, dadas las características propias del soporte que permiten la publicación y la actualización instantáneas de noticias, registró este hecho el mismo día de su ocurrencia, con títulos que se mantuvieron en los primeros lugares de sus homes:

Confirmaron el primer caso de coronavirus en la Argentina (infobae.com); Confirman el primer caso positivo de coronavirus en la Ciudad de Buenos Aires (perfil.com); Coronavirus en la Argentina: primer caso positivo es un hombre de 43 años que estuvo en Europa (ámbito.com); Confirmaron el primer caso de coronavirus en la Argentina (tiempoar.com.ar).

Una vez publicada la noticia, el tema se constituyó en serie periodística ${ }^{2}$, y la prensa creó secciones y clasificaciones especiales (Coronavirus; Coronavirus en Argentina; Cuarentena, entre otras) que, en el presente, organizan diariamente las crónicas que abordan diferentes dimensiones de la problemática.

Este artículo se propone analizar la construcción que los medios de comunicación hacen de la pandemia producida por el coronavirus en Argentina focalizando en la prensa de carácter local ${ }^{3}$, más precisamente de la ciudad de Bahía Blanca, ubicada al sudoeste de la provincia de Buenos Aires. El interés está puesto en el abordaje de la agenda temática sobre la COVID-19, esto es, en los temas o problemas que el principal diario de la ciudad

\footnotetext{
${ }^{1}$ El 11 de marzo de 2020, la Organización Mundial de la Salud anunció que la nueva enfermedad provocada por el coronavirus podía caracterizarse como una pandemia. https://www.who.int/es/dg/speeches/detail/who-director-general-s-opening-remarks-at-themedia-briefing-on-covid-19---11-march-2020

2 Las series informativas están constituidas por noticias que se despliegan espacial y temporalmente en las agendas de los medios durante días o semanas, porque tematizan problemas graves o abiertos que necesitan un desarrollo más amplio. La construcción de series permite la instalación de un problema como relevante en la agenda de un medio y facilita el reconocimiento del público (Martini, 2000).

${ }^{3}$ La denominación "local" se utiliza aquí para hablar de un tipo de prensa que surge y es consumida, fundamentalmente, en una ciudad de provincia y su zona de influencia. Atribuye por ello especial relevancia a asuntos sobre el territorio y la vida cotidiana de la localidad y sus alrededores, con cuyos habitantes establece sólidos lazos (Sánchez, 2018).
} 
y su hinterland, La Nueva, considera relevantes y jerarquiza en un momento particular de tiempo (D’Adamo et al. 2000). Asimismo, se estudian los principales encuadres o frames presentes en los discursos, asumiendo que constituyen marcos interpretativos de la realidad social que tienen impacto en el debate público y en las respuestas que ofrece el sistema político a la problemática. En síntesis, el objetivo principal del trabajo es realizar una aproximación al tipo de información que recibe la sociedad de Bahía Blanca y la región sobre la problemática en un momento crítico mundial.

La elección de la prensa como objeto de estudio toma en cuenta el papel central que este soporte tiene en la construcción de imágenes sobre el país, sus provincias y ciudades (Martini, 2015; Zalba, 2007; Valdettaro, 2005), y en la instalación de la agenda política, social y de otros media. Ese rol se sostiene, e incluso intensifica, durante períodos de crisis social y sanitaria, tal es el caso de las pandemias ${ }^{4}$. Particularmente, el análisis de la producción noticiosa en la prensa de origen local en Argentina es un campo poco frecuentado desde las ciencias de la comunicación, que ha privilegiado el abordaje de diarios editados en la ciudad de Buenos Aires, capital del país. Este estudio propone un enfoque que evita generalizar las manifestaciones culturales del centro hacia todas las regiones del país (Del Palacio Montiel, 2009), y avanza sobre la densidad del significado de las publicaciones de la prensa local, identificando particularidades que resultan de su imbricación con una historia cultural particular.

Dentro del conjunto de los portales informativos existentes en la localidad bahiense y sus alrededores, se selecciona para el análisis a La Nueva por su condición de diario centenario y de referencia en Bahía Blanca y la región, carácter que ha sostenido en su fase digital ostentando los mayores niveles de consumo en su zona de influencia y una mayor amplitud en su abordaje informativo (Orbe y Napal, 2018) ${ }^{5}$.

\footnotetext{
${ }^{4}$ Recientemente, el informe ¿Cómo nos informamos durante la cuarentena? Tecnología, noticias y entretenimiento en tiempos de aislamiento por el covid-19 (2020), realizado por el equipo de Comunicación, Política y Seguridad del Instituto de Investigaciones Gino Germani, registró que, durante la primera fase del ASPO, en el Área Metropolitana de Buenos Aires (AMBA) y la provincia de Buenos Aires las personas se informaron principalmente vía Twitter ( $25 \%$ ) y por la prensa online (22\%), y que dedicaron un promedio de dos horas diarias a la lectura de noticias sobre la pandemia.

${ }^{5}$ La Nueva Provincia, hoy La Nueva, fue creado en 1898 por el periodista Enrique Julio. Durante las dos primeras décadas del siglo XX, fue uno de los más importantes en el campo de la prensa local argentina, también de la provincia de Buenos Aires y del sur del país (Cernadas y Orbe, 2013). En la década del 60 se posicionó como el único diario impreso de la ciudad, y se consolidó como eje de uno de los primeros multimedios del país. En 2012, luego de experimentar transformaciones para reposicionarse en un cambiante
} 
El trabajo se estructura en un apartado metodológico, luego se describen los temas seleccionados y jerarquizados por el medio durante el período estudiado y, a continuación, se analizan los principales encuadres o frames presentes en los discursos. Finalmente, las conclusiones sintetizan hallazgos en torno a los objetivos planteados y posibles líneas futuras de trabajo.

\section{ABORDAJE TEÓRICO METODOLÓGICO}

La propuesta es la identificación, análisis e interpretación de las representaciones discursivas y la construcción de sentidos sobre la pandemia y sus efectos, por lo que la metodología que rige este estudio es predominantemente cualitativa. Se trabaja con herramientas de la teoría de la comunicación, la información y la cultura, y la teoría sobre la noticia inscripta en aquella (Ford, 1994; Martini, 2000). Las técnicas cualitativas permiten abordar la realidad del producto noticioso, esto es, la construcción de la noticia y las agendas, y los posibles modos de apelación al lectorado. El abordaje se complementa con la implementación de técnicas cuantitativas que permiten registrar categorías y coberturas periodísticas buscando la ocurrencia, recurrencia y frecuencia de la información publicada sobre la COVID-19. Estos datos dan cuenta de la relevancia actual de esta agenda y se articulan con producidos desde las técnicas cualitativas.

Dado el volumen informativo publicado sobre el tema desde la llegada del virus a la Argentina, el corpus se construye a partir de la selección de las noticias tomando en cuenta tres "hitos" destacados en la cobertura periodística de la propagación virus en la ciudad y la región: el registro del primer caso infectado por coronavirus en Bahía Blanca (en adelante momento 1 del corpus), la detección de un foco de transmisión en el Hospital Felipe Glasman de la Asociación Médica, que duplica la cantidad de casos registrados en la región (momento 2), y la primera muerte a causa de la COVID-19 en la localidad (momento 3). Las unidades de análisis son las crónicas publicadas en todas las secciones del medio, según resulten pertinentes para la investigación, el día de ocurrencia de estos eventos clave y las jornadas inmediatamente posteriores (20 y 21

entorno mediático, el diario pasó a denominarse La Nueva. El grupo mediático liderado por el periódico continuó en manos de la misma empresa familiar (Julio- Massot) hasta 2016, cuando fue adquirido por los empresarios Elías y Martín. 
de marzo; 15 y 16 de abril; 5 y 6 de mayo, respectivamente). La información se organiza en matrices de datos y gráficos que nos permiten analizar el contenido, construir clasificaciones derivadas del mismo, y realizar una síntesis cualicuantitativa.

\section{LA AGENDA SOBRE LA PANDEMIA EN LA NUEVA}

El 19 de marzo de 2020, el Presidente de la Argentina, Alberto Fernández, dispuso, a partir de la sanción del decreto $297 / 2020$, el aislamiento social, preventivo y obligatorio (ASPO) en todo el país, con el objetivo de frenar el avance del coronavirus en el territorio. La medida regiría a partir del 20 de marzo, fecha que coincidió con la confirmación del primer caso detectado en la ciudad de Bahía Blanca. La persona infectada era un joven de 26 años que había arribado al país y posteriormente a la ciudad proveniente de los Estados Unidos.

Los principales portales digitales de la zona se hicieron eco del acontecimiento y lo construyeron como noticia con titulares como los que siguen: Bahía ya tiene el primer caso de coronavirus confirmado (La Brújula24); Primer caso de COVID-19 en Bahía (Infosexta); Se confirmó el primer caso de coronavirus en Bahía Blanca (Bahía Política); El Coronavirus entró a Bahía Blanca (El Rosaleño); Primer caso de coronavirus en Bahía Blanca (De la Bahía).

En La Nueva, la información llegó a los espacios más jerarquizados de la home, por tratarse de un acontecimiento que cumplía con diversos criterios de noticiabilidad (Rodrigo Alsina, 1989; Sohr, 1998) tales como: la novedad, marca definitoria de este género periodístico, en tanto ruptura de la cotidianidad; la imprevisibilidad, valor que refuerza la marca de la novedad de un hecho apelando a la curiosidad y a la inquietud que provocan los acontecimientos a nivel social (Martini, 2015); la gravedad del fenómeno, por los posibles efectos sobre la comunidad de Bahía Blanca y la zona; la proximidad local y emocional de los hechos con el público del medio, la cantidad de sujetos implicados y afectados; la posibilidad del acontecimiento constituir una serie, ergo, de que se siga construyendo información sobre el mismo a lo largo del tiempo. 
La noticia acerca del avance de la COVID-19 en el mundo ya constituía una serie periodística en el diario de Bahía Blanca, cuya jerarquización garantizó su instalación como agenda urgente. Sin embargo, fue a partir del relato de los hechos locales que las noticias se multiplicaron, clasificadas fundamentalmente en las secciones "La Ciudad" y "La Región", bajo una chapa identificatoria propia: Coronavirus. Desde entonces, este rótulo organiza un conjunto de acontecimientos vinculados con la problemática, a la vez que los clasifica y les otorga relevancia facilitando la percepción y el conocimiento del público.

El día de la confirmación del primer caso (20 de marzo) se publicaron 23 noticias sobre este hecho puntual y acerca de diferentes aspectos del problema, mientras que la jornada posterior se difundieron 14 crónicas. El total de unidades noticiosas publicado en ambos días fue de 37 noticias, un número elevado considerando la cantidad de notas que $L N$ dedicaba con anterioridad, en promedio, diariamente al tema (alrededor de nueve). Por este motivo, el diagnóstico del primer contagiado local es uno de los sucesos que consideramos de alta relevancia en la cobertura del coronavirus.

En el mismo sentido hemos rastreado otros eventos clave tales como la detección de un foco de transmisión en el Hospital Felipe Glasman el 15 de abril, a partir de la infección de 11 empleados/as del centro sanitario y de personas vinculadas con este grupo. El suceso conllevó al cierre del hospital y a la derivación de los pacientes a otras entidades. Entre los días 15 y 16 de abril, la cobertura noticiosa sobre la COVID-19 fue de 20 noticias.

Finalmente, otro hito en la cobertura de la pandemia fue el registro de la primera muerte causada por el virus en la ciudad. La misma ocurrió el 5 de mayo de 2020 en el Hospital Penna. El día del fallecimiento y la jornada subsiguiente se registró un total de 23 noticias en el portal del diario en estudio.

El siguiente gráfico sintetiza la cantidad de crónicas publicadas en torno a los acontecimientos mencionados. 
Gráfico 1. Cantidad de noticias registradas en $L N$ sobre los acontecimientos clave

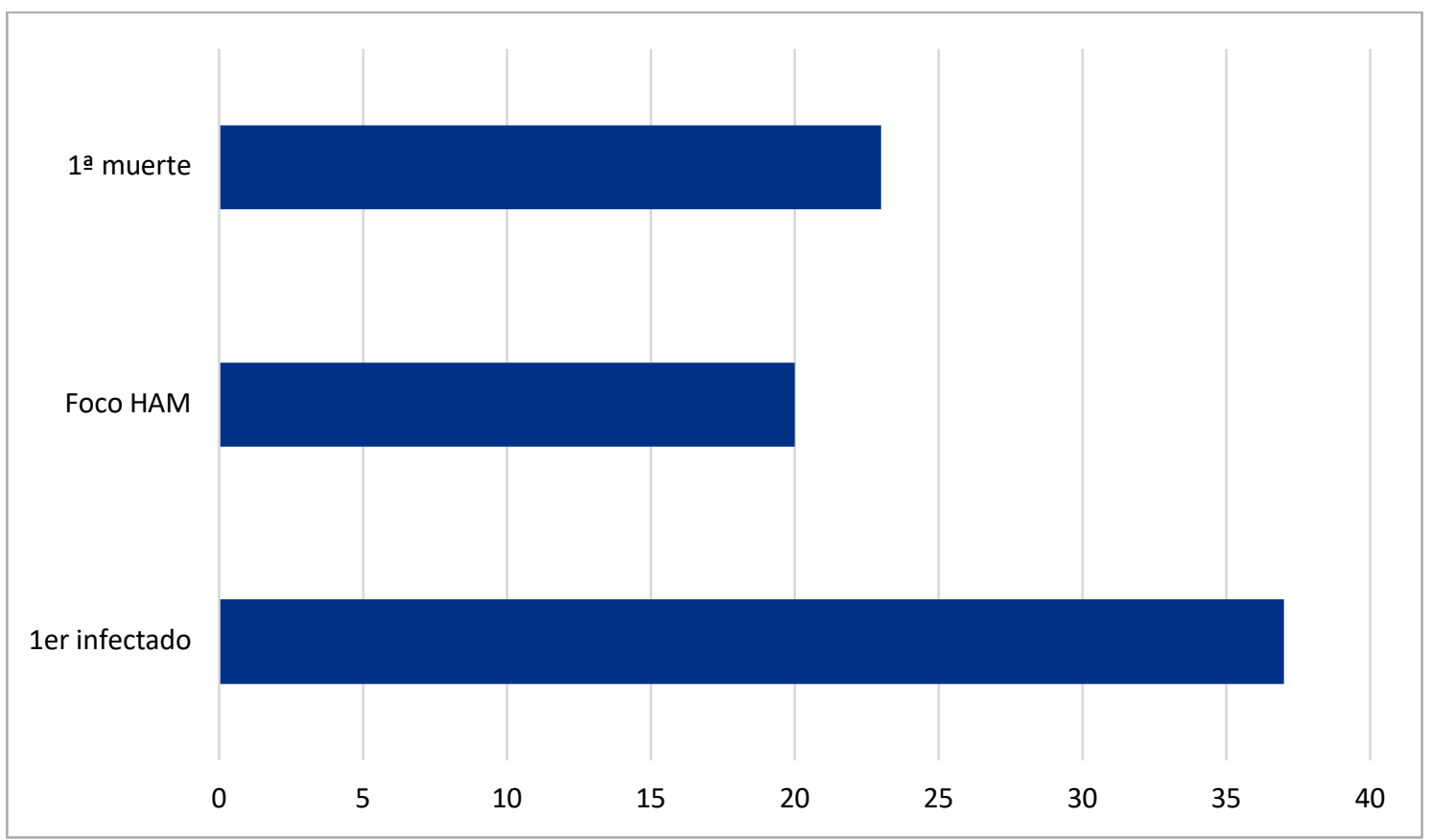

Fuente: elaboración propia

El registro cuantitativo de las noticias en torno a tres momentos clave nos permite, en principio, corroborar el incremento del caudal informativo sobre el coronavirus cuando ocurren episodios portadores de un mayor grado de noticiabilidad, por tratarse de hechos que reportan una situación de mayor gravedad y pueden ser narrados apelando a la conmoción social y el impacto. "Las malas noticias son malas, pero son noticias", afirma Lorenzo Gomis (1991, p. 144) al hablar de las crónicas que denomina "explosiones" -crímenes, catástrofes, desgracias- que representan la irrupción de la alarma en la sociedad, una amenaza a su estabilidad; por su ataque al orden establecido o statu quo.

Vale destacar que las crónicas publicadas no refieren únicamente a los acontecimientos clave identificados, sino a la cobertura de diferentes hechos asociados a la pandemia. Podríamos decir que estos "hitos informativos" operan como puntos de inflexión en la serie periodística sobre la COVID-19 que provocan picos de crecimiento en el volumen de la información publicada.

En consonancia con uno de los objetivos de este trabajo, el relevamiento cuantitativo de crónicas nos habilita a identificar los temas que se asocian a la pandemia en las 
noticias y a crear clasificaciones en relación con los mismos. Ergo, a distinguir diversas series informativas referidas $\mathrm{y} / \mathrm{o}$ conectadas con el problema que se analiza, para identificar qué tipo información recibe la sociedad en un momento de crisis global.

El total de crónicas registradas en el período seleccionado es de 76 unidades, un $79 \%$ de las mismas refiere a la propagación y gestión del problema en Bahía Blanca, y el 21\% restante a localidades más pequeñas, que se incluyen en el área de influencia del diario (Coronel Suárez, Punta Alta, Villarino, Pigué, Viedma, Patagones, Coronel Rosales, Monte Hermoso, entre otras). Tomando en cuenta los temas a los que refieren las noticias, las hemos agrupado en las clasificaciones que citamos a continuación. Incluimos, a modo de ejemplo, dos títulos de cada una de ellas:

- ADMINISTRACIÓN DE LA CIUDAD: Los bancos no atenderán al público hasta el 31 de marzo inclusive (20/3/20); Cómo funcionarán las inmobiliarias en Bahía Blanca (5/5/20).

- DELITO DE SALUD PÚBLICA: Más de 30 personas fueron aprehendidas por no respetar el aislamiento (21/3); Detienen a 186 personas por violar la cuarentena $(5 / 5)$.

- ECONOMÍA: El Municipio prevé una caída de la recaudación del 30 al 40\% en abril y mayo será peor (15/4); Las actividades relacionadas con el campo no están incluidas en la cuarentena (20/3).

- PROgRAMAS, POLÍticas, ACCIONES DEL gobIERNO NACIONAL/PROVINCIAL/LOCAL: Los trabajadores del hospital Municipal recibirán un bono de 5 mil pesos (5/5); Suman nuevas sucursales de la Coope para entrega de cuadernillos escolares (6/5).

- ACCIONES SOlIDARIAS: Campaña solidaria de la Brigada de Socorristas; "Nos cuidamos entre todos" (5/5); La campaña solidaria que se hace en Bahía (21/3). 
- VIDA COTIDIANA/HISTORIAS DE VIDA: La carta de una abuela bahiense aislada que pide volver a besar a sus nietos (20/3); Bahienses que fueron tras un sueño y encontraron una pesadilla (21/3)

- efectos de la pandemia en la salud de la población (TRANSMISIÓN6/MORTALIDAD): Coronavirus en el HAM: "Seguramente van a aparecer más casos" (15/4); Primera muerte por coronavirus en Bahía Blanca (6/5)

- OTRAS: Coronavirus: ¿qué sucede con las mascotas? (20/3).

El siguiente gráfico muestra la clasificación del total de noticias relevadas según el tema.

Gráfico 2. Series periódicas COVID-19

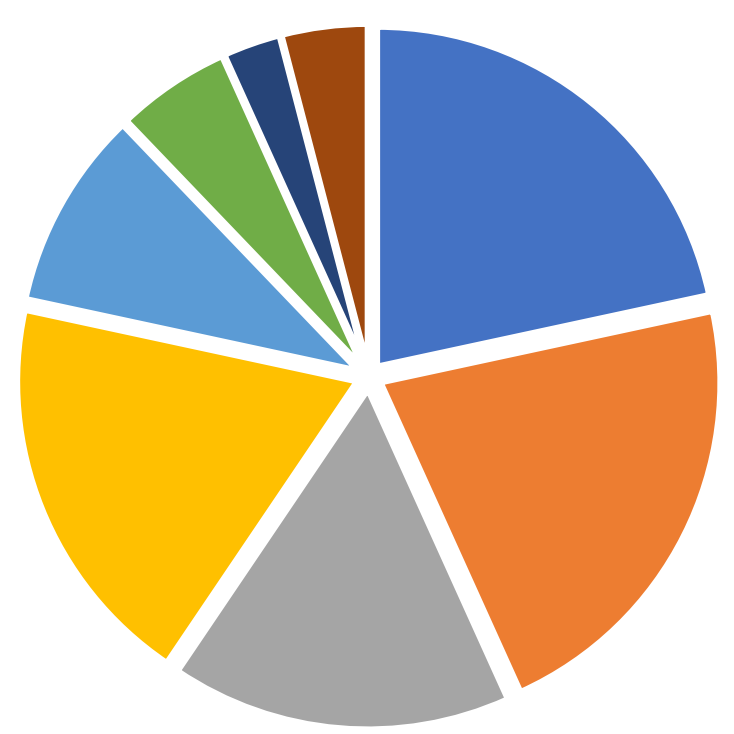

- EFECTOS $\approx$ ECONOMÍA $\approx$ ADM. CIUDAD $\approx$ DELITO SP $\approx$ POL, PROG $\approx$ VIDA COT $\|$ ACC SOL $\approx$ OTROS

Fuente: elaboración propia

En función de la información obtenida a partir del relevamiento, el análisis y la clasificación del corpus expresada en el gráfico, podemos observar que dentro de los temas vinculados con la problemática, los más relevantes en función de su frecuencia

\footnotetext{
6 Tomando en consideración las recomendaciones que la Defensoría del Público de Servicios de Comunicación Audiovisual (Argentina) expresa en el decálogo "Apuntes para las coberturas sobre la pandemia COVID-19", utilizamos la palabra transmisión en lugar de contagio, por ser más precisa en el marco de una pandemia, y porque el vocablo contagio supondría la existencia de una víctima y un victimario.
} 
de aparición son aquellos que refieren a los efectos de la pandemia en la salud de la población (17 notas), esto es, la tasa de transmisión en la ciudad y el número de muertes, y los efectos económicos de la pandemia en la ciudad y la región (16 notas). Las noticias que tematizan delitos de salud pública, puntualmente el registro de violaciones de ciudadanos al ASPO decretado por el gobierno y las diferentes medidas que se toman al respecto, también tienen un lugar destacado en la cobertura que realiza LN (14 notas). Luego, aquellas noticias que informan acerca de cómo se regula la vida cotidiana de la ciudad en función de la pandemia y la medida de aislamiento decretada (el funcionamiento de comercios y las entidades financieras, los horarios de circulación, los permisos necesarios etc.) (12 notas).

En porcentajes mucho más pequeños, aparece la información sobre diferentes políticas y acciones que el gobierno, en sus diferentes niveles, aplica para contener el avance del virus, las historias de vida en tiempos de la pandemia y las acciones solidarias en la ciudad y la región.

La explicación cuantitativa expuesta previamente permite una primera aproximación a la pregunta por el tipo de información privilegiada, difundida y consumida sobre una agenda urgente en la ciudad. Se trata de una descripción que aporta a la relevancia del sentido de nuestro objeto de estudio y dialoga con la interpretación cualitativa que proponemos a continuación.

\section{ENCUADRES PERIODÍSTICOS DE LA PANDEMIA}

\subsection{BREVES NOTAS SOBRE EL FRAMING}

A partir de la selección de los acontecimientos, los periodistas construyen las noticias desde criterios noticiosos y modalidades enunciativas particulares. Este proceso productivo se vincula con la categoría de encuadre o frame, que le da nombre a una teoría que ha tenido un desarrollo notable en los últimos veinte años en los estudios de comunicación ${ }^{7}$.

\footnotetext{
${ }^{7}$ La teoría del framing tiene un origen que fusiona aportes de ciencias diversas, la sociología, la filosofía, la psicología. El concepto aparece por primera vez en los estudios sobre psicología de Gregory Bateson en los años 50, y es retomado luego, en la década del 70, por Ervin Goffman desde un enfoque sociológico, autor que es considerado dinamizador de esta teoría. A partir de entonces, la 
Las investigaciones sobre el papel de los medios en la construcción de realidad y los estudios sobre las agendas se han interesado por la teoría asumiendo que los media no reflejan la realidad pasivamente sino que son parte de una realidad social a la que estos contribuyen con sus propios marcos (cfr. Sádaba, 2007).

Una concepción integral del proceso de encuadre, como la que nos interesa en este trabajo, excede el nivel textual de las noticias, por lo que no sería totalmente equiparable a un conjunto de atributos sobre un tema u objeto. Implica una interacción entre quienes elaboran las noticias y quienes las reciben, que no puede darse por fuera de una cultura a la que ambos pertenecen. Se relaciona, de esta forma, con el modo en que se define y construye un tema público y no simplemente con cómo es presentado. Así, Robert Entman argumenta, en una de las definiciones más citadas en los estudios de comunicación, que

Encuadrar es seleccionar algunos de los aspectos de la realidad percibida y hacerlos más prominentes en un texto que se comunica, de modo que se promueve una definición particular del problema, una interpretación, una valoración moral y/o una recomendación para el tratamiento del ítem que se describe (1993, p. 53).

En los términos planteados, el framing se relaciona con la interpretación del mundo, y se sitúa en el ámbito de la creación de las noticias y agendas (Tuchman, 1978; Sádaba, 2007; Koziner, 2013). Esto permite pensar que es pertinente problematizarlo, entre otros aspectos, en relación con la línea editorial del medio, los temas jerarquizados, las modalidades predominantes en la noticia y con las rutinas productivas de los periodistas.

\subsection{TRATAMIENTO DE LA COVID-19 EN LA PRENSA LOCAL}

De acuerdo a la aproximación teórica señalada, la prensa cumple un rol central en la definición de temas púbicos, no solo en la selección de problemas que alimenta la

teoría del framing se desarrollará en la sociología y también se abordará desde el estudio de los medios de comunicación considerando que los periodistas interpretan realidades para difundirlas a su público. 
discusión pública, sino en la manera de presentarlos y enmarcar el debate (lyengar y Kinder, 1987).

Nos preguntamos entonces, ¿de qué manera presenta La Nueva la problemática de la COVID-19 y sus efectos sobre la sociedad de Bahía Blanca y su zona de influencia? Diversos estudios en el marco de la teoría del framing coinciden en que encuadrar de un modo específico a un tema es atribuirle relevancia, darle prioridad a determinados elementos sobre otros, y así hacerlos más fácil de recordar (Amadeo, 1999). En este sentido, es pertinente considerar que si los marcos, como ideas que organizan las noticias "tienen contenidos manifiestos (...) pero también significados latentes derivados del modo en que el mensaje se expresa, los símbolos y connotaciones insertos en el mensaje y la experiencia de comunicadores y receptores del mensaje" (Graber, 1989 , p. 44), aquello que no aparece en las noticias, o como noticia en una serie, forma parte del proceso de enmarcado y de una definición particular de la problemática.

Partiendo de lo dicho, y retomando los resultados del apartado sobre la agenda temática de La Nueva, una primera aproximación analítica nos permite plantear que en la agenda de la pandemia se le ha dado prioridad a las noticias que refieren a los efectos que el virus tendría sobre la salud de la población (transmisión/mortalidad) y a sus consecuencias sobre la economía del país, y en particular sobre la región de influencia del diario y, en segunda instancia, a las violaciones registradas de la población al ASPO, considerado como un delito de salud pública. Se asume que la jerarquización de estos temas aporta a un enmarcado específico de la problemática, esto es, hay un marco que reduciría el problema fundamentalmente a estos aspectos. Al subrayar lo que se considera relevante, se indicaría aquello a lo que hay que prestarle atención y los términos en que debería darse la discusión.

Más allá de estos resultados, es interesante señalar que cuando analizamos la jerarquización temática para cada momento específico delimitado en el corpus, y ya no para su totalidad, podemos observar algunos cambios.

El día que se identifica el primer caso en la ciudad (20 de marzo), La Nueva comunica en su home que "Se conoció esta tarde el primer caso confirmado de coronavirus en Bahía 
Blanca", la nota describe, en tono informativo, detalles de la persona que contrajo el virus y su estado. El día siguiente informa que "El municipio monitorea a más de 500 personas por el denominado control de foco", enfatizando la actitud resolutiva del gobierno local que busca controlar la situación, las dificultades que se enfrentan y el esfuerzo desplegado. Como se señaló anteriormente, la jornada de detección del primer infectado coincidió con la promulgación del ASPO en el país. Esta primera etapa del corpus es la que recibió mayor cobertura en términos de cantidad de noticias publicadas. Aquí, las noticias se ocupan fundamentalmente de tematizar violaciones al ASPO (10 noticias) y en segundo lugar, de comunicar las nuevas regulaciones para la ciudad ( 8 noticias). No hay en este período mayor información sobre medidas de cuidado y prevención para evitar la transmisión del virus, probablemente porque estas disposiciones aún son confusas a nivel global.

Algunos ejemplos de los asuntos abordados, expresados en titulares del diario son:

Cuarentena total: qué sigue abierto y quiénes pueden ir a trabajar, 20/3.

Gay convocó a las fuerzas armadas y de seguridad para coordinar el control de la cuarentena, 20/3.

De no creer: violó la cuarentena dos veces en 48 horas y ahora está prófugo, 21/3.

Cómo funcionará el servicio especial para trabajadores de la salud, 21/3.

Como se observa en los ejemplos, la pandemia parece alterar la vida cotidiana de la ciudad y sus habitantes, que adquiere por ello una nueva dinámica en su funcionamiento: la clausura de negocios es casi total, se delimitan los servicios esenciales, sólo algunos empleados pueden asistir a sus trabajos, se regula el funcionamiento del transporte público. Asimismo, aparece en las noticias de este primer momento una mirada fuerte de vigilancia y control de las autoridades sobre la población que delimita un encuadre en este sentido y conlleva a que la discusión se oriente en términos de rigor de aplicación de la ley. Al día siguiente de decretar la cuarentena, se informa que "aumentan las detenciones por violarla", "más de 30 personas fueron aprehendidas"; "en el segundo día ya llegan al triple las detenciones en la ciudad". A 
esta representación en la que impera un cierto descontrol de la población, se le opone una construcción que enfatiza las acciones del gobierno en articulación con las fuerzas policiales y armadas, que interpela a la sociedad desde un sentido de gravedad, alarma y urgencia.

Transcurrida la primera etapa de estudio, tanto en el segundo momento del corpus (detección de foco en un hospital) como en el tercero (primera muerte), toman fuerza encuadres vinculados a la dimensión de transmisión del virus (12 noticias) y a las consecuencias del mismo sobre la economía regional (12 noticias). El encuadre que aquí llamamos de transmisión y riesgo se vincula con la ocurrencia de los acontecimientos clave: en principio, los contagios ocurridos en el Hospital de la Asociación Médica implican la duplicación del número de casos registrados hasta ese entonces en la ciudad, y la manifestación de una preocupación por la rotación del personal sanitario por diferentes instituciones. Por ejemplo, en la nota titulada "Hospitales de Bahía: que el problema no se transforme en drama", publicada el 16/4, La Nueva afirma que:

La proliferación de casos positivos dentro del personal hospitalario de Bahía Blanca es un perfecto ejemplo de cómo funciona la cadena de contagios. El 1 de abril se informó que una enfermera contrajo coronavirus en el Hospital de la Asociación Médica (HAM). En principio circuló la versión de que la joven de 23 años formaba parte del equipo que atendía a los pacientes contagiados, pero luego se supo que se desempeñaba en un área diferente del hospital (...) Es decir, 13 sobre 22 casos detectados en Bahía Blanca forman parte del mismo encadenamiento (16/4).

De manera complementaria, el conocimiento de la primera muerte a causa del virus en la ciudad, también favorece un tratamiento de las noticias que enfatiza en el riesgo de transmisión y en posibles nuevos decesos. Se observa en titulares como:

Primera muerte por coronavirus en Bahía Blanca (05/05), Patagones: una persona en estudio, 64 descartados y la incertidumbre por el único caso positivo (06/05), Trabajador, familiero y servicial: quién era Egidio, la primera víctima del coronavirus en Bahía (06/05); Bahienses que fueron tras un sueño y encontraron una pesadilla (06/05). 
En las crónicas de la segunda y tercera etapa, la situación se define en términos de preocupación, proliferación de casos, cadena de contagios, pesadilla, muerte, atributos que se resaltan en el tratamiento periodístico y permiten la identificación del encuadre citado. Este frame sostiene una coherencia con el criterio de noticiabilidad de la gravedad y la imprevisibilidad de los hechos, central en la selección de los acontecimientos que constituyen la serie sobre la pandemia.

En tanto, las noticias que refieren al impacto de la COVID- 19 sobre la economía dan cuenta de una preocupación que, si bien toma carácter nacional, es enfatizada por el diario a escala local, reforzando el contrato de lectura del medio que apunta a la cercanía con el lector medio del diario.

Transcurrido casi un mes de la promulgación del decreto de aislamiento, las restricciones a las diferentes actividades han sido detalladas de manera más clara por los gobiernos local, provincial y nacional, los efectos de la pandemia sobre el sistema productivo de la región se hacen evidentes y el diario cuenta con datos que le permiten trazar proyecciones a corto y mediano plazo. En la nota titulada "El Municipio prevé una caída de la recaudación del 30 al 40\% en abril y mayo será peor", se lee:

Una fuerte baja en los ingresos sufrirán este mes todos los niveles del Estado y el Municipio de Bahía Blanca no será la excepción. Teniendo en cuenta que el aislamiento obligatorio comenzó el día 20 de ese mes, se proyecta que el descenso en la recaudación será del mencionado 30 a 40 \%. Pero la principal preocupación pasa por mayo, cuando haya que cobrar acorde a lo facturado en abril, un período de bajísima actividad salvo en sectores muy puntuales como los supermercados (15/4).

A partir del énfasis que el diario pone, en esta y otras noticias del corpus, en las consecuencias que la pandemia y la cuarentena tienen y podrían tener sobre la economía local delimitamos un encuadre al que denominamos desastre económico. Este tipo de cobertura puede pensarse también en un contexto que excede el actual, y que se articula con los marcos socio históricos del diario. Como se ha trabajado en otros artículos (Sánchez, 2012 y 2019) Bahía Blanca es una las ciudades portuarias e industriales más importantes de la Argentina. Desde fines del siglo XIX, tiene un lugar de relevancia en el mapa económico 
del país derivado de su ubicación estratégica y de las cualidades del territorio. La Nueva, cuyo surgimiento es contemporáneo a este momento histórico, construye desde entonces una imagen de ciudad en constante crecimiento, líder del sudoeste bonaerense, destinada a un a la grandeza y a un brillante porvenir ${ }^{8}$ (Llull, 2013; Silva, 1998). Entendemos que este frame sociohistórico presiona sobre la construcción noticiosa, por eso la dimensión económica de la pandemia es jerarquizada como tema, y todo factor que afecte el desarrollo productivo de la región, construido en términos de alerta y amenaza.

Interesa destacar que, más allá de la detección de encuadres noticiosos particulares que organizan la información en los diferentes momentos del corpus, se identifica un encuadre que atraviesa el período completo estudiado. A los fines analíticos, podríamos llamarlo frame de la omnipresencia, entendiendo esta cualidad como un rasgo sobresaliente de la cobertura. La omnipresencia de la temática en la agenda del diario se plasma no solo en su permanencia como serie periodística sino en la representación de la problemática como un presente continuo: el virus podría estar en cualquier parte, el contagio ocurrir de manera azarosa, todas las dimensiones de la vida social y cotidiana se encuentran afectadas. Las noticias advierten sobre la transmisión en hospitales, el transporte público, cruceros que quedan varados en el exterior, zonas blindadas, comercios que cierran, actividades agropecuarias (prioritarias en la zona) frenadas, educación suspendida en todos sus niveles ${ }^{9}$.

Se podría asumir que, en la articulación de este presente permanente del relato con el presente de la lectura sincrónica de la prensa digital, se instala una actualidad de amenaza e incertidumbre; el peligro de la transmisión, del descontrol, de una crisis económica en ciernes parece inminente.

Finalmente, si, como señalamos anteriormente, los frames funcionan para dar mayor o menor relevancia a ciertos temas e ideas, e incluso volver invisibles a otros (cfr. Entman,

\footnotetext{
${ }^{8}$ La Nueva, denominación abreviada de La Nueva Provincia, tiene en el origen de su nombre la voluntad de ser la cabeza de una provincia separada de Buenos Aires, y reivindica esta potencialidad en una aparente grandeza y un brillante porvenir de Bahía Blanca. La tapa del primer número del diario (1898) lleva una leyenda que lo acompañará hasta 2013, y que plasma lo señalado en una frase de su fundador Vengo a luchar en pos de una idea grande que encarna para el sur argentino la génesis de un brillante porvenir.

${ }^{9}$ Las situaciones descriptas corresponden a diferentes circunstancias narradas en el corpus. Por cuestiones de espacio no se incluyen en este caso fragmentos y/o titulares de las noticias.
} 
1993), Ilama la atención la escasa presencia de noticias del corpus que refieren a políticas públicas y acciones que el gobierno, en sus diferentes niveles, aplica o se propone aplicar para contener el avance del virus y proteger a la población. En el período estudiado se han identificado solo 7 noticias sobre este tópico sobre un total de 76, cantidad que representa un $9 \%$ de lo publicado.

Considerando el rol preponderante que los medios de referencia poseen en la construcción y atribución de sentido social, y que, especialmente en contextos de crisis social, "la información puede contribuir a tomar decisiones de la población para mitigar los efectos del riesgo" (Defensoría del Público, 2020, s/p), se entiende que la difusión de estas acciones constituye información socialmente necesaria para la población (Schiller, 1996).

En este punto, consideramos que el tratamiento escaso de las políticas públicas y del desempeño de actores políticos como tema de agenda forma parte del proceso de enmarcado y de una definición particular de la problemática. Aunque este trabajo aborda un corpus pequeño, podemos arriesgar que su omisión da cuenta de una construcción informativa desde marcos que reducen la problemática a otras aristas, posiblemente en conexión con aquellas que merecen la atención de las autoridades a las que el diario interpela y del universo sociocultural de lectores al que apunta. Queda para próximos estudios explorar como opera en esta construcción periodística el posicionamiento del gobierno local, opositor a los gobiernos provincial y nacional en ejercicio, y sus potenciales relaciones con el diario.

\section{DISCUSIÓN Y CONCLUSIONES}

La irrupción y el avance de la COVID-19 constituyen, actualmente, la agenda informativa hegemónica en los medios de comunicación de la Argentina y el mundo.

En este trabajo se avanzó sobre los modos en qué la problemática se construye en la prensa local argentina; focalizando en La Nueva, diario de referencia de la ciudad Bahía Blanca y su área de influencia. Mediante un análisis cuantitativo de las noticias publicadas sobre el coronavirus en torno a tres eventos clave, se elaboraron clasificaciones según los temas/dimensiones de la problemática que aquellas 
abordaban. Los resultados arrojaron que estos son, según su ocurrencia y frecuencia: los efectos del virus en la salud de la población, las consecuencias económicas de la pandemia en la región y los delitos de salud pública.

Tomando este panorama como base, se avanzó en un estudio cualitativo de los datos centrado en el abordaje de los principales frames que organizan la información. A partir del análisis de noticias, hemos identificado algunos encuadres que, en tanto definiciones de situación, son comunes a la totalidad del corpus. Así, se caracterizó un frame de la omnipresencia, sustentado en la aparición continua del tema como serie, y en el tratamiento atributivo otorgado al mismo. LA COVID-19 es construida en las noticias como una amenaza constante, un presente continuo y azaroso que altera la vida cotidiana y social de los habitantes de la ciudad y su hinterland. Asimismo, los encuadres que denominamos de transmisión y riesgo, y del desastre económico, aunque están presentes en notas de todo el corpus, se enfatizan en la segunda y tercera etapa del mismo, sustentados en las crónicas sobre la detección de un foco de contagio en un hospital y en la primera muerte. El tratamiento informativo en estos momentos subraya un estado de alarma por la posibilidad de nuevos contagios, la saturación del sistema sanitario local, posibles nuevos fallecimientos, y el riesgo de un colapso económico que atente contra el lugar de privilegio histórico de la ciudad y la región en el mapa nacional.

A diferencia de lo señalado, en la primera etapa del corpus identificamos que se otorga prioridad a la información sobre la nueva administración de la ciudad a partir del decreto del ASPO, y, fundamentalmente, a la necesidad de vigilancia frente a potenciales y efectivas violaciones al mismo. El encuadre que prima es el que llamamos de vigilancia y control.

Finalmente, destacamos el escaso tratamiento de noticias destinadas a comunicar las acciones y políticas públicas puestas en marcha o planificadas por los gobiernos local, provincial y nacional para hacer frente a la situación; información de alta relevancia para la toma de decisiones de la población para mitigar los riesgos adoptando medidas de prevención.

Interesa destacar que este trabajo constituye un estudio de caso realizado en tiempo real. En el contexto de un problema aún en desarrollo, no tiene pretensiones de 
generalización sino de presentar tendencias en los modos de construir información sobre temas urgentes en medios de diverso alcance geográfico. Asimismo, de poner el foco en el rol trascendental que estos poseen por su posibilidad de actuar como caja de resonancia y marcos cognitivos desde los que la sociedad interpreta la realidad. En ese sentido, planteamos la responsabilidad que les compete a nivel social cuando se trata de difundir información considerada de interés público o socialmente necesaria.

Este artículo podría ser punto de partida de otros futuros, donde sería pertinente ampliar el período temporal abordado, e incluso plantear la comparación con otros medios nacionales y/o internacionales, con la finalidad de identificar continuidades y discontinuidades en el tratamiento de una agenda global urgente.

\section{REFERENCIAS BIBLIOGRÁFICAS}

Amadeo, B. (1999). La aplicación de la teoría del framing a la cobertura de la corrupción política en Argentina (1991-1996) [tesis doctoral]. Universidad de Navarra, Facultad de Comunicación, Pamplona, España.

D'adamo, O. J., Beaudoux, V. G. y Freidenberg, F. (2000). Medios de comunicación, efectos políticos y opinión pública: ¿una imagen, vale más que mil palabras? Buenos Aires: Editorial de Belgrano.

Defensoría del Público SCA (2020). Apuntes para las coberturas sobre la pandemia COVID-19. Recuperado de https://defensadelpublico.gob.ar/recomendaciones-para-lacobertura-de-la-pandemia-covid-19/

Del Palacio Montiel, C. (2009). Una mirada a la historia de la prensa de México desde las regiones. Un estudio comparativo (1792-1950). Revista Historia Iberoamericana, 2(1), 80-97.

Entman, R. (1993). Framing: Toward clarification of a fractured paradigm. Journal of Communication, 43(4), 51-58. https://doi.org/10.1111/j.1460-2466.1993.tb01304.x

Ford, A. (1994). Navegaciones. Comunicación, cultura y crisis. Buenos Aires: Amorrortu. 
Gomis, L. (1991). Teoría del periodismo. Cómo se forma el presente. Barcelona: Paidós.

Graber, D. (1989). Content and memory. What is it all about. American Behavioral Scientist, 33(2), 144-152.

Iyengar, S. y Kinder, D. R. (2010). News that matters: Television and American opinion. Chicago: University of Chicago Press.

Koziner, N. (2013). Antecedentes y fundamentos de la teoría del framing en comunicación. Austral comunicación, 1(2), 01-25.

Llull, L. (2001). Bahía Blanca, prensa y política en la Liverpool del Sur. 1900-1936. En L. Prislei (Dir.), Pasiones sureñas. Prensa, cultura y política en la frontera norpatagónica (1884-1946). Buenos Aires: Prometeo.

Martini, S. (2000). Periodismo, noticia y noticiabilidad. Buenos Aires: Norma.

Martini, S. (2015). Medios y sociedad. Las agendas del delito en la prensa gráfica y digital y en la televisión en la Argentina. En M. Degoumois (Dir.), Delitos y medios masivos de comunicación. Aportes para la reflexión acerca de los discursos sobre violencia y criminalidad (pp. 255-278). Buenos Aires: Ministerio de Justicia y Derechos Humanos de la Nación.

Orbe, P. y Napal, M. (2018). Los medios de comunicación en la ciudad: del papel a la era digital. En M. Cernadas y J. Marcilese (Coords.), Bahía Blanca siglo XX. Historia política, económica y sociocultural (pp. 273-304). Bahía Blanca: EdiUNS.

Rodrigo Alsina, M. (1989). La construcción de la noticia. Barcelona, Paidós.

Sádaba, T. (2007). Framing: el encuadre de las noticias. El binomio terrorismo- medios. Buenos Aires: La Crujía.

Sánchez, R. (2012). Nación, identidad y construcción del control en la prensa conservadora. Los casos de La Nación y La Nueva Provincia. En S. Martini y M. E. Contursi (Comps.). Comunicación pública del crimen y gestión del control social (pp. 253-281). Buenos Aires: La Crujía. 
Sánchez, R. (2018). El delito en la prensa gráfica argentina. Un estudio en diarios nacionales y provinciales (2012-2014). (Tesis doctoral). Facultad de Ciencias Sociales, Universidad de Buenos Aires, Buenos Aires, Argentina.

Sánchez, R. (2019). Inseguridad y delito en la prensa regional y local argentina. Revista Comunicación, Política y Seguridad, 1(1). Recuperado de https://publicaciones.sociales.uba.ar/index.php/revistacomunicacion/article/view/354 $8 / 2867$

Schiller, H. (1996). Information inequality. Nueva York: Routledge.

Silva, H. (1998) "Un destino manifiesto". 1898 - 1998. Cien años de periodismo. Bahía Blanca: La Nueva Provincia.

Sohr, R. (1998). Historia y poder de la prensa. Barcelona: Andrés Bello.

Tuchman, G. (1978). News making. A study in the construction of reality. New York: The Free Press.

Valdetattaro, S. (2005). Prensa y temporalidad. La trama de la comunicación, 10, 97104.

Verón, E. (1983) Construir el acontecimiento. Buenos Aires: Gedisa.

Zalba, E. (2007). Una aproximación al <orden del discurso> periodístico. Boletín de la $B C N$, Biblioteca del Congreso de la Nación, 123.

\section{DIARIOS CONSULTADOS}

La Nueva: https://www.lanueva.com/

Clarín: https://www.clarin.com/

La Nación: https://www.lanacion.com.ar/

Página 12: https://www.pagina12.com.ar/

Tiempo Argentino: https://www.tiempoar.com.ar/ 
Infobae: https://www.infobae.com/

Perfil: https://www.perfil.com/

La Brújula24: https://www.labrujula24.com/

Infosexta: https://infosexta.com.ar/

Bahía Política: https://bahiapolitica.com/

El Rosaleño: http://elrosalenio.com.ar/

De la Bahía: http://www.delabahia.com.ar/ 